\title{
INFLUENCE OF NISIN AND LAURYL ARGININE ESTER AGAINST SOME FOODBORNE PATHOGENS IN RECOMBINED FETA AND PROCESSED SPREAD CHEESE
}

\author{
TAREQ M. AL-NEMR', SAMEH E. MOHAMED², ALBERTO BARBABOSA ${ }^{3}$ and ABDELFATTAH Z.M. SALEM 3,4 \\ 'Department of Dairy Science and Technology, Faculty of Agriculture, Alexandria University, Alexandria, Egypt \\ 2Department of Food Technology, Arid Lands Cultivation and Research Institute (ALCRI), City of Scientific Research and Technological Applications \\ (SRTA - City), Borg El-Arab, Egypt \\ ${ }^{3}$ Facultad de Medicina Veterinaria y Zootecnia, Universidad Autónoma del Estado de México, Toluca, C.P. 50000, Mexico
}

${ }^{4}$ Corresponding author.

TEL: 00521-722-296-55-42;

FAX: 00521-722-180-61-94;

EMAIL: asalem70@yahoo.com

Received for Publication March 11, 2015

Accepted for Publication July 13, 2015

doi: $10.1111 /$ jfs. 12224

\begin{abstract}
The aim of this study was to evaluate the impact of nisin with lauryl arginine ester (LAE) or their combination by 1: $3(\mathrm{w} / \mathrm{w})$ on cheese preservation. The study was carried out against the most common foodborne pathogens in recombined feta cheese (RFC) and processed cheese spread (PCS). Combination of nisin with LAE has higher synergistic preservative effect on different widespread foodborne pathogens such as Bacillus subtilis, Clostridium sporogenes and Escherichia coli compared with individual one. The most sensitive strain was E. coli with an effective minimal inhibition concentration (MIC) of $400 \mathrm{ppm}$, whereas the former spore-forming bacterial strains were totally inhibited using $700 \mathrm{ppm}$ from the combination, respectively. Synergistic combination blend was added by its recommended MIC (700 ppm) in the manufacture of both RFC and PCS. The results indicated that it is efficient enough to inhibit the growth of the most common foodborne pathogens in cheese after their storage for 7 days (RFC) and 30 days (PCS).
\end{abstract}

\section{PRACTICAL APPLICATIONS}

Inhibiting the foodborne pathogens by the addition of lauryl arginine ester (LAE) and nisin together by $1: 3(\mathrm{w} / \mathrm{w})$ increased the cheese quality. However, the possibility of contamination of traditional cheese during the preservation in terms of food safety can be controlled by the addition of the two mentioned additives (i.e., LAE and nisin) and can be manufacture and distribute in the dairy industries.

\section{INTRODUCTION}

In developing countries where warm humid climate and bad storage conditions prevail, large amounts of dairy products are lost every year due to spoilage caused by the growth of several foodborne microorganisms that grow during their storage periods. Milk-borne outbreaks were responsible for $25 \%$ of all outbreaks due to contaminated food and water (United States Public Health Service and Food and Drug Administration 2011). Even today, human illnesses related to the consumption of unpasteurized and also pasteurized dairy products remain a public health problem
(Anaelom et al. 2010; European Food Safety Authority 2012).

Among dairy pathogens, Bacillus and Clostridium (grampositive spore-forming thermoduric bacteria) are considered to be the most existing pathogens in various dairy products (Papademas 2015). Some species of Bacillus are capable of producing gastroenteritis such as B. cereus and B. coagulans or producing anthrax such as B. anthracis, whereas some species of Clostridium are responsible for gastroenteritis (C.perfringens) and botulism (C. botulinum) (Papademas 2015). Sperber and Doyle (2010) reported that the latter pathogens are responsible for a variety of cheese 
defects, such as excessive softening of cheese, splits and cracks, off-flavors and abnormal color. Latter sporeformers produce spores that can survive after pasteurization, causing several microbiological defaults after vegetation (Munsch-Alatossava and Alatossava 2006). According to Sharaf et al. (2014), the prevalence rates of Bacillus and Clostridium spp. were 2 and $1 \%$ in recombined feta cheese (RFC) samples, respectively. As for processed cheese spread (PCS), another study reported about the same percentages in the PCS samples (Glass and Doyle 2013).

Some other serotypes of pathogenic Escherichia coli are associated frequently with milk spoilage and several publications have been published on their pathogenicity (Oliver et al. 2009). Pathogenic E. coli pathotypes can be divided into two large groups. The intestinal pathogenic E. coli not only colonize human intestine but also cause diseases ranging from mild diarrhea to severe colitis and dysentery as well. The extraintestinal pathogenic E. coli reside in the intestine asymptomatically but can cause severe infection upon reaching extraintestinal niches such as the urinary tract or bloodstream (Shpigel et al. 2008). About the prevalence of E. coli in milk, a recent study (Garnica et al. 2013) reported that a total of 752 bulk tank milk samples from 205 dairy sheep flocks belonging to Consortium for Ovine Promotion were collected between January and December 2011. Four samplings were carried out in each flock, one per season, throughout one year. E. coli was present in $17.4 \%$ of the samples and $50.7 \%$ of the flocks throughout the year. It was also reported the prevalence of E. coli was at its highest limit in autumn and winter coinciding with a rainy weather. Post-contamination may occur after milk pasteurization and this is the only critical hazard step that could permit E. coli to post-contaminate pasteurized milk, RFC and PCS and grows further.

Since food safety is an imperative issue for consumers, food manufacturers and government officials (Hoffmann et al. 2012), several methods were reported to preserve food. Among such methods is the use of food-grade natural preservatives to extend the shelf life of food products. Nisin is a well-known broad spectrum Food and Drug Administration (FDA)-approved bacteriocin active against gram-positive pathogens associated with foods (Delves-Broughton 2014). Its use as a food biopreservative is limited by the lack of effect against gram-negative bacteria. Moreover, the development of nisin resistance has been reported in sensitive gram-positive pathogens such as some mutants of Bacillus and Clostridium (Zhou et al. 2014) at normal concentrations. Furthermore, Zapico et al. (1999) reported that nisin was absorbed to protein and fat globules in dairy products, thus preventing its activity.

Several studies have shown that the nisin spectrum activity may be extended to gram-negative bacteria such as E. coli by using it in combination with other agents (Cutter and Siragusa 1995a). Many reports have been published on the synergistic antimicrobial effects of nisin with sucrose fatty acid esters (Thomas et al. 1998), the lactoperoxidase system (Boussouel et al. 1999), thymol (Ettayebi et al. 2000) and carbon dioxide (Nilsson et al. 2000).

Lauryl arginine ester (LAE) is a cationic surfactant, ethyl$\mathrm{N} \alpha$-lauroyl-L-arginate- $\mathrm{HCl}$, which has a broad inhibitory spectrum against gram-positive and gram-negative bacteria, yeasts and molds (Bakal and Diaz 2005). It may be demonstrated as ethyl lauroyl arginate which acts as a potential alternative for some of the currently approved preservatives such as sulfites, benzoates and sorbates, which have some inherent limitations (Exposito 2006).

The mode of action of ethyl lauroyl arginate includes surface tension reduction and the formation of ionic aggregates leading to changes in the conductivity and solubility of cell membranes that can lead to permanent alterations in cell permeability and growth inhibition or microorganism inactivation (Rodriguez et al. 2004).

Therefore, this study was performed to apply hurdle technology via determining the synergistic effect of nisin and LAE on RFC as well as PCS as models of comment consumed cheese in Egypt. Synergistic combination was also examined for its antimicrobial activity against the most widely spread foodborne spore-formers (Bacillus subtilis and Clostridium sporogenes) and the common food spoilage microorganism (E. coli).

\section{MATERIALS AND METHODS}

\section{Bacterial Strains and Media}

B. subtilis DB100 host was obtained from the Department of Food Technology, Faculty of Agriculture, Alexandria University. C. sporogenes DSM1446 was provided by Department of Dairy Science and Technology, Faculty of Agriculture, Alexandria University. E. coli DH5 $\alpha$ (wild type) was obtained from Genetic Engineering and Biotechnology Research Institute (GEBRI), City for Scientific Research and Technological Applications (SRTA-City). B. subtilis and E. coli strains were grown in Luria-Bertani medium (Atlas 2004) at 37C. C. sporogenes was grown in the Reinforced Clostridial Medium (RCM) medium (Atlas 2004) at 37C.

\section{Chemicals}

Nisinpro (nisin) was purchased from Zhengzhou ChiHon Biotechnology Co., Ltd. (Chihonbio, China). LAE was obtained from Vedeqsa (Barcelona, Spain). Nisin as well as LAE stock solutions were prepared as $10,000 \mathrm{ppm}$ and were sterilized using $0.45-\mu \mathrm{m}$ filter paper (Sigma, Munich, Germany) and kept in a refrigerator at $4 \mathrm{C}$ until use. 


\section{RFC Processing}

According to Robinson and Tamime (1996), a mix preparation in the APV Flex-Mix Instant was prepared. The RFC ingredients were as follows: $20 \%$ palm oil, $8 \%$ skimmed milk powder, $7.2 \%$ milk protein concentrate (70\% protein), 2.6\% sodium chloride, 2.8\% GDL (Gluco Delta Lactone), $0.1 \%$ potassium sorbate and the examined preservatives (nisin or LAE or their combinations). The Flex-Mix Instant tank is filled with water. The temperature is dependent on the fat/stabilizer requirement. Melted fat is pumped into the Flex-Mix Instant tank under vacuum and during high shear mixing, forming an oil-in-water emulsion. Functional milk proteins, stabilizers and other dry ingredients are also added to the instant tank under vacuum and during high shear mixing. After mixing, a suitable hydration time is applied. After sufficient hydration, the mix is pasteurized and cooled. Rennet and other acidifying ingredients such as GDL were added. At this stage, nisin (at serial concentrations from 100 to $1,000 \mathrm{ppm}$ ) or LAE (at serial concentrations from 100 to $1,000 \mathrm{ppm}$ ) or their combinations (from 1:1 to $1: 5$ and vice versa) were added separately for each preparation and the mix is filled into packs. Finally, salt is added and acidification takes place at mesophilic temperature. For positive controls of RFC, Bacillus as well as Clostridium cultures were added at $\left(2 \times 10^{4} \mathrm{cfu} / \mathrm{mL}\right)$ to reconstituted milk before pasteurization step, while E. coli culture was added at $\left(2 \times 10^{4} \mathrm{cfu} / \mathrm{mL}\right)$ after pasteurization step to stimulate that post-contamination has occurred. The RCF and their controls samples were collected after storage for 3 days at $4 \mathrm{C}$ for further microbiological analysis since the cheese was spoiled after 7 days of storage period.

\section{PCS Preparation}

PCS was prepared as described by Meyer (1973). PCS was made in pilot processing machine (WOLF Anlagen-Technik $\mathrm{GmbH}$ \& Co. KG Geisenfeld, Germany) at 1,400 rpm, homogenization at 200 bar, total time of acidification is $2 \mathrm{~min}$ and heating was at $85 \mathrm{C} / 6 \mathrm{~min}$. Fifty percent of the total amount of water was added before heat treatment, the rest of the amount of water was added when temperature reached $98 \mathrm{C}$ and then the temperature was dropped rapidly to $86 \mathrm{C}$. At this stage, nisin (at serial concentrations from 100 to $1,000 \mathrm{ppm}$ ) or LAE (at serial concentrations from 100 to $1,000 \mathrm{ppm}$ ) or their combinations (from 1:1 to $1: 5$ and vice versa) were added separately for each preparation, and then the cheese was filled at 74C.

The major steps in process cheese manufacture can be divided into two stages. The first stage consists of ingredient formulation including selection and grinding of natural cheese (on the basis of age, $\mathrm{pH}$, flavor and intact casein content), selection of appropriate emulsifying salt, and formation and computation of other ingredients (in order to meet the targeted moisture, fat, salt and $\mathrm{pH}$ values of the final product as per governmental regulations). The second stage consists of process cheese processing and storage. The ingredient blend is processed using heat and mixing to produce a homogeneous mass, which is packaged and cooled. The minimum cook temperature (indirect heating) and time specified for PCS was used (FDA 2006) to preserve the organoleptic properties of the final cheese. For positive controls of PCS, Bacillus as well as Clostridium cultures were added at $\left(2 \times 10^{4} \mathrm{cfu} / \mathrm{mL}\right)$ to reconstituted milk before pasteurization step, while E. coli culture was added at $\left(2 \times 10^{4} \mathrm{cfu} / \mathrm{mL}\right)$ after pasteurization step to stimulate that post-contamination has occurred. The PCS and their controls samples were collected after storage for 3 days for further microbiological analysis and the cheese was left for an extended storage period until its spoilage (after 30 days).

\section{RCF Cheese Preparation for Microbiological Analysis}

According to Kourkoutas et al. (2006), representative 10-g portions of duplicate samples and controls taken from the cheese interior were blended with $90 \mathrm{~mL}$ of sterilized Ringer solution (1/4 strength) and subjected to serial dilutions.

\section{PCS Cheese Preparation for Microbiological Analysis}

According to Muir et al. (1999), representative 10-g portions of duplicate samples and controls taken from the cheese interior were dispersed in $90 \mathrm{~mL}$ sterile solution of trisodium citrate $(0.07 \mathrm{M} / \mathrm{L})$ and subjected to serial dilutions.

\section{Inhibitory Effect of Either Nisin or LAE or Their Preferred Combination (1:3, w/w)}

According to Mayr-Harting et al. (1972), RFC and PCS and their prepared samples for microbiological analysis were subjected to serial dilutions. Each dilution was spread over a Petri dish containing nutrient agar (Difco, NJ, USA). Colonies were counted after overnight incubation of inoculated Petri dishes at the optimum growth conditions (37C, aerobically for the detection of each E. coli and Bacillus, and 37C anaerobically for the detection of Clostridium).

\section{RESULTS}

\section{Antimicrobial Activity of Nisin}

After $24 \mathrm{~h}$ of incubation, it was observed that nisin has an ascending antimicrobial activity against B. subtilis DB100 host and C. sporogenes DSM1446 with its gradual increase 


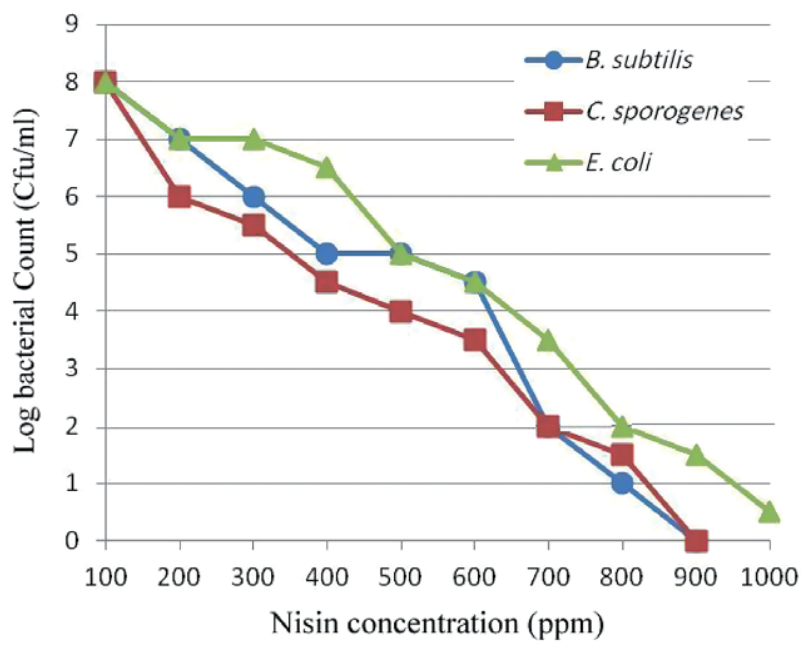

FIG. 1. ANTIMICROBIAL ACTIVITY OF NISIN AGAINST Bacillus subtilis DB100 HOST (•), Clostridium sporogenes DSM1446 (ם) AND Escherichia coli DH5A (WILD TYPE) $(\mathbf{A})$

in concentration. However, it has a weak antimicrobial activity against E. coli DH5 $\alpha$ (wild type) (Fig. 1). The nisin minimal inhibition concentration (MIC) was $900 \mathrm{ppm}$ for B. subtilis DB100 host and C. sporogenes DSM1446 and $1,000 \mathrm{ppm}$ for E. coli DH5 $\alpha$. Even after using 1,000 ppm nisin, E. coli DH5 $\alpha$ formed very tiny colonies, indicating its bacteriostatic rather than bactericidal activity. Figure 2 shows that the nisin MIC that inhibited both B. subtilis DB100 host and C. sporogenes DSM1446 did not affect the growth of E. coli $\mathrm{DH} 5 \alpha$ completely.

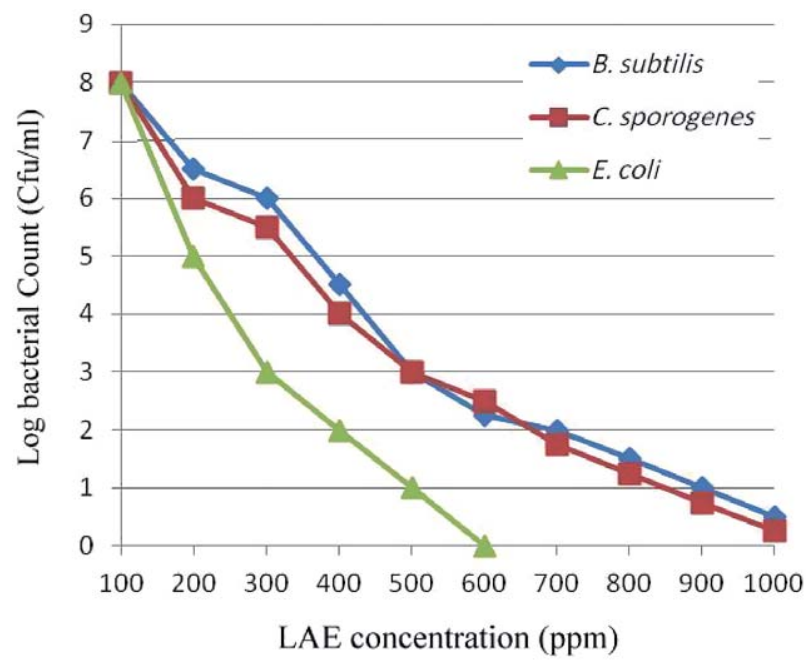

FIG. 3. ANTIMICROBIAL ACTIVITY OF LAE AGAINST Bacillus subtilis DB100 HOST ( $\bullet$ ), Clostridium sporogenes DSM1446 (घ) AND Escherichia coli DH5A (WILD TYPE) (

\section{Antimicrobial Activity of LAE}

The antimicrobial activity of LAE was investigated against B. subtilis DB100 host, C. sporogenes DSM1446 and E. coli $\mathrm{DH} 5 \alpha$ (wild type). LAE had a strong activity against E. coli $\mathrm{DH} 5 \alpha$ (wild type) after $24 \mathrm{~h}$ of incubation (Fig. 3) as it needed only $600 \mathrm{ppm}$ LAE to be completely inhibited. However, it had moderate antimicrobial activity against both B. subtilis DB100 host and C. sporogenes DSM1446 as
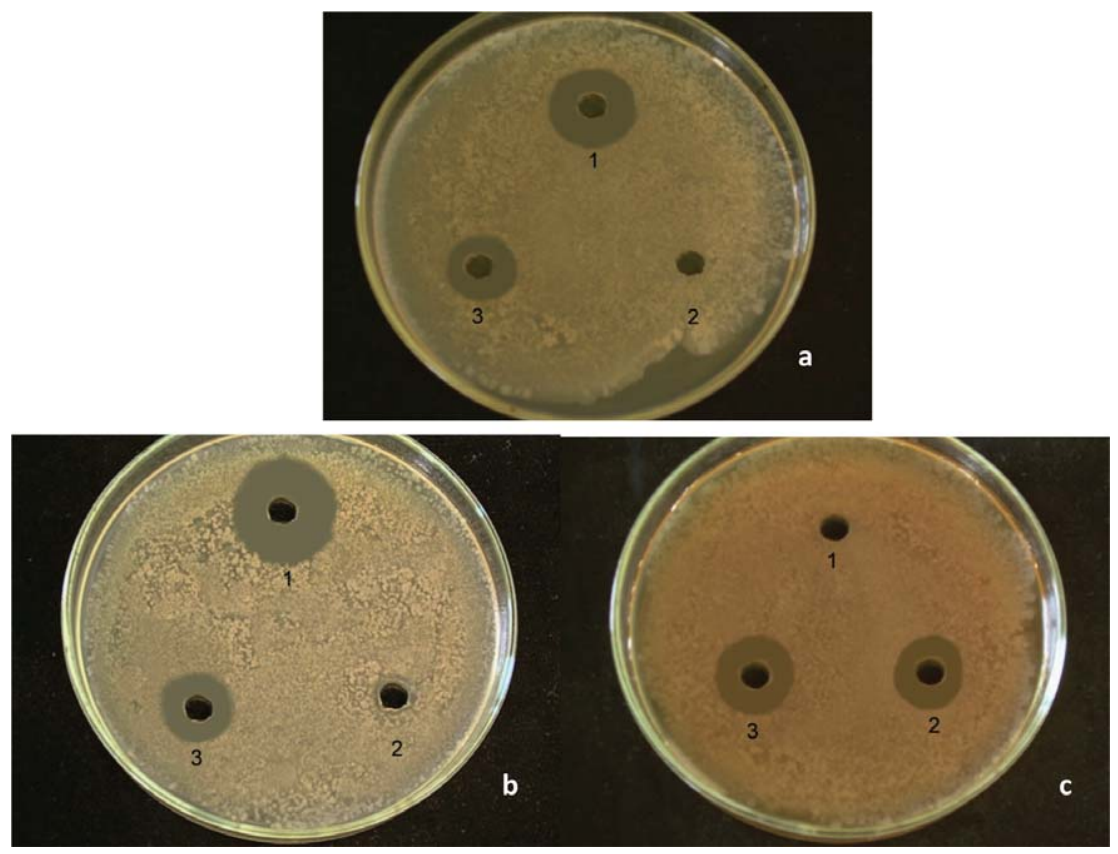

FIG. 2. THE EFFECT OF NISIN (1) OR LAE (2) OR THE BLEND (3) ON Bacillus subtilis DB100 HOST (A) OR Clostridium sporogenes DSM1446 (B) OR Escherichia coli DH5A (C) 


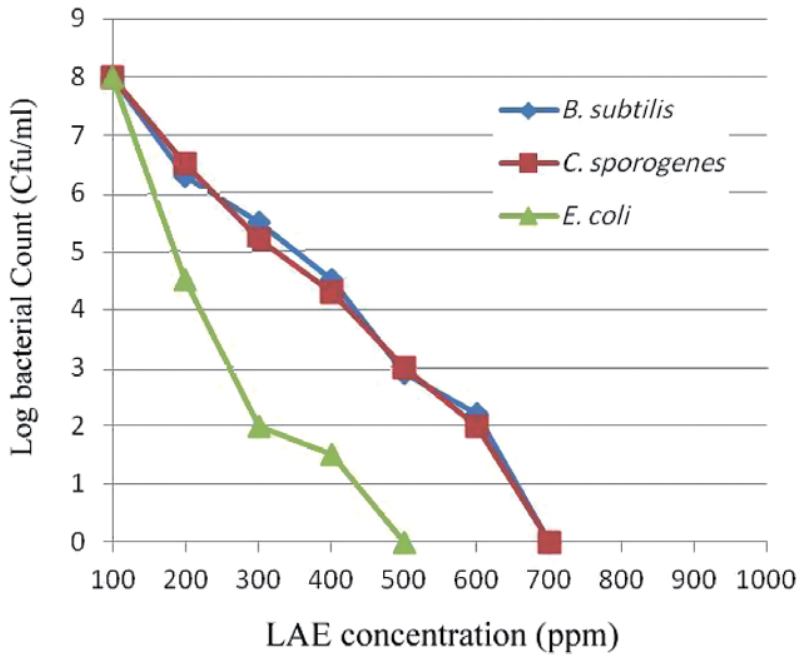

FIG. 4. ANTIMICROBIAL ACTIVITY OF SYNERGISTIC COMBINATION AGAINST Bacillus subtilis DB100 HOST $(\bullet)$, Clostridium sporogenes DSM1446 (ם), AND Escherichia coli DH5A (WILD TYPE) $(\boldsymbol{\Delta}$

their LAE MIC was 1,000 ppm. Even after using 1,000 ppm LAE, B. subtilis and C. sporogenes continued to grow due to the nonspecificity of LAE to influence different grampositive bacteria. Figure 2 shows that the nisin MIC that inhibited both B. subtilis DB100 host and C. sporogenes DSM1446 did not affect the growth of E. coli DH5 $\alpha$ completely.

\section{Synergistic Effect of Nisin and LAE against Pathogens}

It was observed that nisin in combination with different concentrations of LAE (1:2 and 1:3 w/w) had a strong antimicrobial activity with a clear synergistic effect. The synergistic combination minimal antimicrobial concentration (MIC) was $700 \mathrm{ppm}$ for both B. subtilis DB100 host and C. sporogenes DSM1446 and $400 \mathrm{ppm}$ for E. coli DH5 $\alpha$. Such concentrations are significantly low in comparison with that of nisin and LAE separately. Figure 4 indicates the antimicrobial activity of synergistic combination against the above pathogens. From the previous figure, it was indicated that the synergistic combination that composed of nisin : LAE (by 1:3, w/w) is the most efficient blend regarding its strong antimicrobial activity than other blends. Figure 2 shows that the mixture MIC inhibited B. subtilis DB100 host, C. sporogenes DSM1446 and E. coli DH5 $\alpha$ completely.

\section{Synergistic Combination Usage in RFC and PCS Manufacture}

Synergistic combination blend (nisin : LAE; 1:3, w/w) was proven to be the most efficient blend added by its recom-

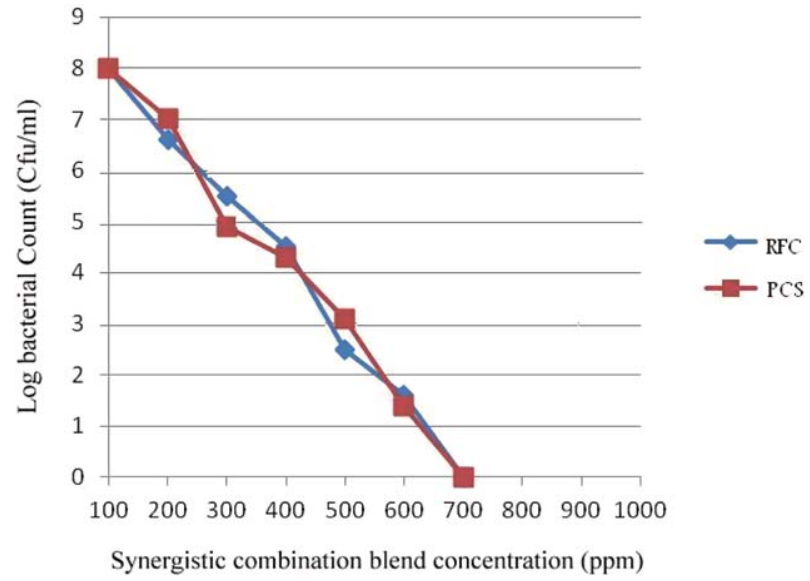

FIG. 5. EFFECT OF SYNERGISTIC COMBINATION BLEND (700 PPM) THAT INHIBITS THE GROWTH OF FOODBORNE PATHOGENS IN RECOMBINED FETA CHEESE (RFC) ( $\bullet$ AND PROCESSED CHEESE SPREAD (PCS)

mended MIC (700 ppm) in the manufacture of both RFC and PCS. The results indicated in Fig. 5 showed that such concentration of synergistic combination was efficient enough to inhibit the growth of the most common foodborne pathogens in cheese after their storage for 7 days (RFC) and 30 days (PCS).

\section{DISCUSSION}

The emergence of B. subtilis, C. sporogenes and E. coli as important foodborne pathogens has led to a resurgence of interest in antimicrobials suitable for their control; however, consumer demand for foods that contain fewer artificial preservatives and more natural food stuffs has increased (Gould 1992). To address both these issues, much research has focused on the potential of LAE as a cationic surfactant with a very broad spectrum of activity against different microorganisms for its use in food preservation (Bakal and Diaz 2005). For example, it was used against Salmonella typhimurium and Staphylococcus aureus (Rodriguez et al. 2004) and Listeria monocytogenes (Luchansky et al. 2005). It is hydrolyzed in the human body and it was regarded "generally recognized as safe" (GRAS) by the FDA (Exposito 2006). However, in the present study, LAE (1,000 ppm) was not enough to inhibit spore-forming bacteria such as Bacillus and Clostridium completely by its own activity.

On the contrary, nisin is a well-known antimicrobial agent naturally produced by Lactococcus lactis ssp. lactis and used industrially against different gram-positive bacteria. Recently, some nisin-resistant strains of foodborne grampositive pathogens have emerged. Furthermore, we have 
noticed that nisin has a weak antimicrobial activity against E. coli which is one of the most common gram-negative pathogen.

Multiple combination preservation technique, or so-called hurdle technology, has been defined by Leistner (2000) as an intelligent combination of hurdles, which secures the microbial safety and stability as well as the organoleptic and nutritional quality and the economic viability of food products. For example, several antimicrobial compounds could be used together with different combinations to broaden the inhibitory spectrum to a degree that could not be reached by using each compound alone. The antimicrobial combinations should have different mechanisms to attain synergistic activity (Smid and Gorris 1999).

Extending the spectrum of nisin activity to gramnegative bacteria is also being examined. The application of nisin in combination with food-grade chelating agents is reported to increase the inhibitory activity and inhibitory spectrum of nisin (Cutter and Siragusa 1995a; Shefet et al. 1995). The use of nisin in combination with other bacteriocins such as Pediocin $\mathrm{AcH}$ has been reported to demonstrate greater antibacterial activity against a greater number of gram-positive bacteria (Hanlin et al. 1993). Nisin in combination with lactate has been found to reduce the numbers of S. typhimurium attached to beef and nisin in combination with ethylenediaminetetraacetic acid (EDTA) has been reported to reduce the numbers of E. coli O157:H7 attached to beef (Branen and Davidson 2004). Moreover, Kopermsub et al. (2012) tried to encapsulate nisin and EDTA combinations by nanoencapsulation technology in niosomes and investigated their synergistic effect on S. aureus and E. coli. However, EDTA has its own cautions. For example, it can cause the breathing tubes to narrow in some people with asthma, make heart rhythm problems worse, interfere with blood sugar control because it can interact with insulin, decrease serum calcium, potassium and magnesium levels (making hypocalcemia, hypokalemia and hypomagnesemia worse), make liver and kidney diseases worse, increase the risk of seizure in people with epilepsy or in people who tend to have seizures (Crisponi et al. 2014).

Another study noticed the synergistic activity of nisin and monolaurin (LAE is one of its derivatives) on Bacillus ssp. vegetative cells in milk (Mansour and Milliere 2001). They reported that the use of these inhibitors separately induced an immediate reduction in the bacterial population level but transient because re-growth appeared and was strain-dependent. However, the use of these inhibitors in combination induced a synergistic bactericidal effect, leading to a total inhibition until day 5 , except in the case of $B$. cereus where the monolaurin concentration was doubled until the end of the experiment; consequently, sporulation was absent. However, Mhatre and Singare (2013) reported that the usage of monolaurin is found to be cytotoxic than LAE.

FDA has affirmed that nisin derived from certain strains of L. lactis ssp. lactis is GRAS for use as an antimicrobial agent in various cheese products such as cheese spreads and processed cheese when used at a level that delivers a maximum of $250 \mathrm{ppm}$ of nisin in the finished product (21 CFR 184.1538). Nisin can also be used in meat and poultry at $600 \mathrm{ppm}$ when the meat is fully cooked and used as a component in sauces. Under these conditions, the meat and poultry cannot be more than $50 \%$ of the product. On the other hand, FDA has affirmed that LAE is also GRAS for use as an antimicrobial agent in various cheese and other fermented dairy products when used at a level that delivers a maximum of 3,714 ppm of LAE in the finished product as if we exceed such level the LAE toxicity symptoms will appear (21 CFR 170.36). In our study, we used a combination of nisin : LAE (by 1:3, w/w) at $700 \mathrm{ppm}$. This means that the total concentration of nisin in our combination is about $234 \mathrm{ppm}$ and the total concentration of LAE in our combination is about $525 \mathrm{ppm}$ and both concentrations are under the permitted levels recommended by the FDA.

In the present study, it was found that LAE with various combinations of nisin has a great influence as an antimicrobial agent with significant synergistic activity against different common foodborne pathogens in RFC and PCS. Such approach could be a potential antimicrobial combination that may be used in dairy industries to prolong the shelf life of different fermented dairy products.

\section{CONCLUSION}

It was found that LAE and nisin synergistically and significantly inhibited the growth of B. subtilis, C. sporogenes and E. coli. Thus, the results of the study indicate that such a combination of synergistic combination blend (nisin : LAE; $1: 3, \mathrm{w} / \mathrm{w}$ ) has a significant value to be applied in milk industries as a potential food preservative.

\section{ACKNOWLEDGMENTS}

We would like to thank Prof. Ahmed Rafik and Prof. Ali Khattab (Faculty of Agriculture, Alexandria University), and Dr. Hesham Mostafa (City for Scientific Research and Technological Applications) for their assistance in providing us with the bacterial cultures needed to perform most of experiments of the present study.

\section{REFERENCES}

ANAELOM, N.J., IKECHUKWU, O.J., SUNDAY, E.W. and NNAEMEKA, U.C. 2010. Zoonotic tuberculosis: A review of 
epidemiology, clinical presentation, prevention and control. J. Public Health Epidemiol. 2, 118-124.

ATLAS, R.M. 2004. Handbook of Microbiological Media, Vol. 159, pp. 623-624, CRC Press, Florida, USA.

BAKAL, G. and DIAZ, A. 2005. The lowdown on lauric arginate. Food Qual. 12, 54-61.

BOUSSOUEL, N., MATHIEU, F., BENOIT, V., LINDER, M., REVOL-JUNELLES, A.M. and MILLIERE, J.B. 1999. Response surface methodology, an approach to predict the effects of a lactoperoxidase system, Nisin, alone or in combination, on Listeria monocytogenes in skim milk. J. Appl. Microbiol. 86, 642-652.

BRANEN, J.K. and DAVIDSON, P.M. 2004. Enhancement of nisin, lysozyme, and monolaurin antimicrobial activities by ethylenediaminetetraacetic acid and lactoferrin. Int. J. Food Microbiol. 90, 63-74.

CRISPONI, G., NURCHI, V.M., LACHOWICZ, J.I., CRESPO-ALONSO, M., ZORODDU, M.A. and PEANA, M. 2014. Kill or cure: Misuse of chelation therapy for human diseases. Coord. Chem. Rev. 284, 278-285.

CUTTER, C.N. and SIRAGUSA, G.R. 1995a. Population reduction of Gram-negative pathogens following treatments with nisin and chelators. J. Food Prot. 58, 977-983.

DELVES-BROUGHTON, J. 2014. Nisin, Encyclopedia of Food Microbiology, pp. 187-193, Academic Press, Elsevier, London, UK.

ETTAYEBI, K., YAMANI, J. and ROSSI-HASSANI, B.D. 2000. Synergistic effects of nisin and thymol on antimicrobial activities in Listeria monocytogenes and Bacillus subtilis. FEMS Microbiol. Lett. 183, 191-195.

EUROPEAN FOOD SAFETY AUTHORITY. 2012. European Centre for Disease Prevention and Control. The European Union Summary Report on Trends and Sources of Zoonoses, Zoonotic Agents and Food-borne Outbreaks in 2010. EFSA Journal 10(3), 2597 [pp. 1-442]. doi:10.2903/j.efsa .2012.2597. http://www.efsa.europa.eu/en/efsajournal/doc/ 2597.pdf (accessed February 21, 2012).

EXPOSITO, J.A.C. 2006. Studies on antimicrobial activity of arginine-based surfactants and chemo-enzymatic synthesis of novel amphiphiles based on L-arginine and D-fagomine. $\mathrm{PhD}$ Thesis, Universidad Autónoma de Barcelona, Barcelona, Spain.

FDA. 2006. Food and Drug Administration: CFR Title 21. 133.169-133.180, Department of Health and Human Services, Washington, DC.

GARNICA, M.L., LINAGE, B., CARRIEDO, J.A., SANTOS, J.A. and GONZALO, C. 2013. Staphylococcus aureus and Escherichia coli prevalence in ovine bulk tank milk. Small Ruminant Res. 115, 108-110.

GLASS, K. and DOYLE, M.E. 2013. Safety of PCS, FRI Briefings Bulletin. Food Research Institute, University of Wisconsin-Madison.

GOULD, G.W. 1992. Ecosystem approaches to food preservation. J. Appl. Bacteriol. 21, 58-68.
HANLIN, M.B., KALCHAYANAND, N., RAY, P. and RAY, B. 1993. Bacteriocins of lactic acid bacteria in combination have greater antibacterial activity. J. Food Prot. 56,

252-255.

HOFFMANN, S., BATZ, M.B. and MORRIS, J.G., Jr. 2012. Annual cost of illness and quality-adjusted life year losses in the United States due to 14 food borne pathogens. J. Food Prot. 75, 1292-1302.

KOPERMSUB, P., MAYEN, V. and WARIN, C. 2012. Nanoencapsulation of nisin and ethylenediaminetetraacetic acid in niosomes and their antibacterial activity. J. Sci. Res. 4 , 457-465.

KOURKOUTAS, Y., KANDYLIS, P., PANAS, P., DOOLEY, J.S.G., NIGAM, P. and KOUTINAS, A.A. 2006. Evaluation of freeze-dried Kefir coculture as starter in Feta-type cheese production. Appl. Environ. Microbiol. 72, 6124-6135.

LEISTNER, I. 2000. Basic aspects of food preservation by hurdle technology. Int. J. Food Microbiol. 55, 181-186.

LUCHANSKY, J.B., CALL, J.E., HRISTOVA, B., RUMERY, L., YODER, L. and OSER, A. 2005. Viability of Listeria monocytogenes on commercially-prepared hams surface treated with acidic calcium sulfate and lauric arginate and stored at 4 degrees C. Meat Sci. 71, 92-99.

MANSOUR, M. and MILLIERE, J.-B. 2001. An inhibitory synergistic effect of a nisin-monolaurin combination on Bacillus sp. vegetative cells in milk. Food Microbiol. 18, 87-94.

MAYR-HARTING, A., HEDGES, A.H. and BERKELEY, R.C.W. 1972. Methods for studying bacteriocins. In Methods in Microbiology (J.R. Norris and D.W. Ribbons, eds.) pp. 315-422, Academic Press, New York, NY.

MEYER, A. 1973. PCS Manufacture, 1st Ed., Food Trade press Ltd., London, U.K.

MHATRE, J.D. and SINGARE, P.U. 2013. Comparative study on cytotoxicity activity of $\mathrm{N}-\alpha$-acylarginine ethyl ester. Int. Lett. Chem., Phys. \& Astro. 8, 1-7.

MUIR, D.D., TAMIME, A.Y., SHENANA, M.E. and DAWOOD, A.H. 1999. Processed cheese analogues incorporating fat-substitutes 1 . Composition, microbiological quality and flavour changes during storage at $5{ }^{\circ} \mathrm{C}$. Lebensm.-Wiss. Technol. 32, 41-49.

MUNSCH-ALATOSSAVA, P. and ALATOSSAVA, T. 2006. Phenotypic characterization of raw milk-associated psychrotrophic bacteria. Microbiol. Res. 161, 334-346.

NILSSON, L., CHEN, Y., CHIKINDAS, M.L., HUSS, H.H., GRAM, L. and MONTVILLE, T.J. 2000. Carbon dioxide and nisin act synergistically on Listeria monocytogenes. Appl. Environ. Microbiol. 66, 769-774.

OLIVER, S.P., BOOR, K.J., MURPHY, S.C. and MURINDA, S.E. 2009. Food safety hazards associated with consumption of raw milk. Foodborne Pathog. Dis. 6, 793-806.

PAPADEMAS, P. 2015. Dairy Microbiology: A Practical Approach, CRC Press, Florida, U.S.A.

ROBINSON, R.K. and TAMIME, A.Y. 1996. Feta and Related Cheeses, Woodhead Publishing Limited, England. 
RODRIGUEZ, E., SEGUER, J., ROCABAYERA, X. and MANRESA, A. 2004. Cellular effects of monohydrochloride of L-arginine, N-lauroyl ethyl ester (ethyl lauroyl arginate) on exposure to Salmonella typhimurium and Staphylococcus aureus. J. Appl. Microbiol. 96, 903-912.

SHARAF, O.M., IBRAHIM, G.A., TAWFEK, N.F., EFFAT, B.A.M., EL SHAFEI, K., EL-DIN, H.M.F. and SALEM, M.M.A. 2014. Prevalence of some pathogenic microorganisms in factories Domiati, RFC and UHT milk in relation to public health sold under market conditions in Cairo. Int. J. ChemTech Res. 6, 2807-2814.

SHEFET, S.M., SHELDON, B.W. and KLAENHAMMER, T.R. 1995. Efficacy of optimized nisin based treatments to inhibit Salmonella typhimurium and extend shelf life of broiler carcasses. J. Food Prot. 58, 1077-1082.

SHPIGEL, N.Y., ELAZAR, S. and ROSENSHINE, I. 2008. Mammary pathogenic Escherichia coli. Curr. Opinion in Microbiol. 11, 60-65.

SMID, E.J. and GORRIS, L.G.M. 1999. Natural antimicrobials for food preservation. In Handbook of Food Preservation (M.S. Rhaman, ed.) Marcel Dekker, New York.
SPERBER, W.H. and DOYLE, M.P. 2010. Compendium of the Microbiological Spoilage of Foods and Beverages, Springer, New York, U.S.A.

THOMAS, L.V., DAVIES, E.A., DELVES-BROUGHTON, J. and WIMPENNY, J.W. 1998. Synergist effect of sucrose fatty acid esters on nisin inhibition of Gram-positive bacteria. Appl. Environ. Microbiol. 85, 1013-1022.

UNITED STATES PUBLIC HEALTH SERVICE AND FOOD AND DRUG ADMINISTRATION. 2011. Grade "A" pasteurized milk ordinance. http://www.fda.gov/downloads/ Food/GuidanceRegulation/UCM291757.pdf (accessed December 15, 2011).

ZAPICO, P., MEDINA, M., GAYA, P. and NUNA, E.Z.M. 1999. Synergistic effect of nisin and the lactoperoxidase system on Listeria monocytogenes in skim milk. Int. J. Food Microbiol. 40, 35-42.

ZHOU, H., FANG, J., TIAN, Y. and LU, X.Y. 2014. Mechanisms of nisin resistance in Gram-positive bacteria. Ann. Microbiol. 64, 413-420. 